引用格式: 于立宏, 王艳, 陈家宜. 考虑环境和代际负外部性的中国采矿业绿色全要素生产率 [J]. 资源科学, 2019, 41(12): 21552171. [Yu L H, Wang Y, Chen J Y. Green total factor productivity of Chinese mining industries considering negative intergenerational and environmental externalities[J]. Resources Science, 2019, 41(12): 2155-2171.] DOI: 10.18402/resci.2019.12.01

\title{
考虑环境和代际负外部性的中国采矿业绿色 全要素生产率
}

\author{
于立宏, 王 艳, 陈家宜
}

(华东理工大学商学院, 上海 200237)

\begin{abstract}
摘 要: 中国采矿业具有代际负外部性和环境负外部性特征,但传统的全要素生产率不考虑负外部性影响,而 现有绿色全要素生产率测算也仅考虑环境污染,难以真实衡量采矿业的效率与绿色技术进步。本文构建了考虑双 重负外部性的绿色全要素生产率测度框架,基于 2005-2015 年采矿业的省级面板数据测算其变动率,并将绿色全 要素生产率分解为技术进步、规模报酬、代际负外部性、环境负外部性等, 以考察其关键影响因素和传导机制。结 果显示: (1) 考虑环境和代际双重负外部性的绿色全要素生产率普遍低于传统全要素生产率的结果。(2)采矿业的绿 色全要素生产率均有显著增长, 其中, 黑色金属开采业增速最快, 其次为煤炭开采业和有色金属开采业, 油气开采 业最低。(3)代际和环境负外部性因素对绿色全要素生产率皆呈现抑制作用, 但对不同产业的抑制程度存在异质 性。环境负外部性对煤炭开采业和有色金属开采业的绿色全要素生产率具有较高的抑制作用, 而代际负外部性对 油气开采业和黑色金属开采业的抑制作用则高于其他采矿业。
\end{abstract}

关键词: 采矿业; 绿色全要素生产率; 代际负外部性;环境负外部性

DOI :10.18402/resci.2019.12.01

\section{1 引言}

采矿业作为上游部门,为下游加工业提供基础 原材料, 在推动中国经济高速增长中起到举足轻重 的作用。改革开放 40 年来, 中国采矿业实现了快速 增长和结构优化。截至2016年, 中国规模以上采矿 企业约 1.25 万家, 产值 4.62 万亿元, 占全部工业企 业总产值的比重为 $3.3 \%$, 占主营业务收人的比重为 $4.1 \%{ }^{[1]}$ 。中国采矿企业的规模结构也在不断优化, 集约化程度不断提升, 平均资产收益率普遍高于工 业平均水平, 劳动生产率整体呈现上升趋势。

然而, 中国采矿业也长期存在过度进人、产能 过剩等问题, 因过度开采导致的环境负外部性与代 际负外部性问题非常突出, 致使资源耗竭和生态环 境恶化加剧 ${ }^{[2]}$ 。根据中国环境统计年鉴的数据, 采 矿业产生的固体废弃物是工业固体废弃物的主要
来源, 在 2005-2016 年间平均占比达到 $40 \%$ 以上， 2012 年甚至高达 $48.8 \%$ 。同时, 40 年来中国矿产资 源探明储量增长十分缓慢, 但消费增速却远高于世 界平均水平,采矿业的可持续发展面临严峻挑战。 2009 年, 煤炭基础储量开始出现负增长, 导致煤炭 资源的可开采年限快速下降, 2011 年仅为 67.6 年, 远低于世界平均水平; 而石油储采比仅为 15 年左 右; 铅、锌可开采年限低于 10 年。

在中国经济向高质量发展转型的重要时期, 《中共中央国务院关于加快推进生态文明建设的意

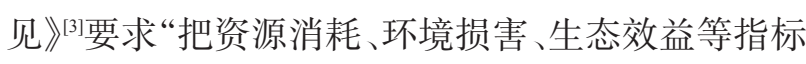
纳人经济社会发展综合评价体系”。因此,采矿业 必须加快绿色技术进步, 缓解资源和环境约束, 推 动产业转型升级, 实现绿色发展。本文定义采矿业 绿色全要素生产率为同时考虑环境负外部性和代 
际负外部性的全要素生产率, 即要求其将双重负外 部性引致的社会成本内部化, 准确度量其真实的全 要素生产率水平。唯有如此,绿色全要素生产率才 能用以衡量经济、资源与环境绩效的共赢状态。

研究表明,依赖资源消耗或重污染产业的国 家, 生产率往往被高估, 而注重资源高效利用或污 染减排的国家,生产率则往往被低估 ${ }^{[4]}$ 。也就是说, 如果遗漏环境污染排放和自然资源使用因素, 容易 带来误导和决策失误。这是由于传统的全要素生 产率并未考虑资源与环境的影响, 因而无法准确考 察经济增长和产业发展所付出的全部代价。近年, 很多学者通过考虑环境负外部性测算了绿色全要 素生产率 ${ }^{[-7]}$, 但这些文献缺乏针对采矿业的研究。本 文重新定义了绿色全要素生产率概念, 并通过构建 考虑双重负外部性的模型进行了测度。此外, 本文 还研究了全部采矿业子行业的绿色全要素生产率, 并通过对比分析, 试图把握这些产业的共性与异质 性, 以便更为精准地为政府制定政策提供依据。具 体地, 本文将资源、环境、经济增长纳人一个统一的 分析框架, 从超越对数成本函数出发, 通过核算两 种负外部性成本, 并基于修正索洛余值模型, 构建 了一个考虑双重负外部性的绿色全要素生产率测 度框架, 全面评估采矿业的绿色技术进步水平。

\section{2 文献综述}

国内外关于绿色全要素生产率的研究经过了 从单纯考虑环境负外部性到同时考虑资源耗减的 转变, 在研究方法上不断创新, 这其中涉及到负外 部性在全要素生产率测算过程中的应用。因此, 本 文的文献综述涉及代际负外部性与环境负外部性 的概念、绿色全要素生产率的内涵和全要素生产率 的研究方法以及涉及相关产业的实证研究。

可耗竭资源产生的代际负外部性概念源于 Hotelling ${ }^{[8]}$ 的研究, 后来由 Arrow 等 ${ }^{[9]} 、$ Solow ${ }^{[10]}$ 等加以 深化,其涵义是: 作为“交易内部人”的一代人的资 源开采成本的增加被强加于作为 “交易外部人” 的 未来若干代人身上, 而这种成本增加并未由产生成 本的内部人加以偿付, 从而损害了代际公平。这一 负外部性是矿产资源开采业所独有的特性。环境 负外部性被定义为:生产和消费过程中消费者效用 和企业成本所受到的环境影响并未得到补偿的部
分 ${ }^{[1]}$, 广泛存在于所有产业。实际上,两种负外部性 都可被理解为生产过程中私人成本和社会成本的货 币化差额,这导致市场均衡产量大于社会最优产 量, 均衡价格小于最优价格, 由此造成社会福利净 损失。然而, 企业缺乏主动将负外部性成本内部化 的动机, 在一定程度上使得其生产率容易被高估。

绿色全要素生产率本质上是实现资源节约利 用、污染排放减少和劳动生产率提高的过程 ${ }^{[12]}$ 。优 化绿色全要素生产率是对环境全要素生产率的持 续改善 ${ }^{[13]}$ 。最初的绿色全要素生产率是将污染排放 作为产出,测算考虑环境因素的全要素生产率。诸 多学者在测算区域和行业层面全要素生产率的基 础上对经济发展方式和发展绩效进行评价 ${ }^{[14-16]}$ 。随 着全社会对资源与环境约束的重视,不少学者研究 包含资源及环境要素的绿色全要素生产率测算框架, 以反映资源投入和环境污染给生产率带来的影响。 同时,绿色全要素生产率还与不同资源消耗程度和 污染程度有关, 如果遗漏环境污染排放、资源投人

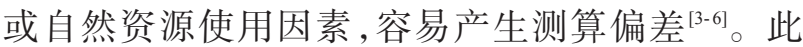
外,绿色发展方式注重低能源消耗、低污染排放,也 需要在全要素生产率分析框架中纳人能源消耗和环 境污染因素 ${ }^{[5,6]}$ 。目前, 大部分研究支持资源与环境 问题对绿色全要素生产率具有制约作用的结论 ${ }^{[17-19]}$ 。

在采矿业全要素生产率研究方面,现有成果不 多,主要可分为两类:一类是在研究工业全要素生 产率时涉及采矿业,但这类研究的重点放在提升生 产率的轨迹精度和微观分解上, 仅将采矿业作为样 本的一部分, 且没有考虑双重负外部性。与工业全 要素生产率相比,煤炭和石油天然气行业全要素生 产率普遍较低, 远低于工业平均水平 ${ }^{[20,21]}$, 且采矿业 全要素生产率增长率总体呈现逐年递减的态势 ${ }^{[22]}$ 。 然而, 若考虑资本与劳动投人对经济增长的贡献, 采矿业全要素生产率的增速则是最快的 ${ }^{[23]}$; 另一类 是针对某个采矿业的绿色全要素生产率研究,但这 类研究要么仅考虑环境因素的影响, 要么仅考虑资 源耗减因素。当考虑环境负外部性时,工业绿色全 要素生产率低于传统测量方法,特别是采矿业受到 的影响非常明显。其中, 黑色金属、有色金属以及 非金属开采业的全要素生产率出现下降 ${ }^{[24]}$; 对煤炭 企业的研究发现,环境污染甚至导致全要素生产率 出现负增长 ${ }^{[25]}$ 。当考虑资源耗减因素时, Rodriguez 
方法无法将矿产资源的代际负外部性问题引入模

等 ${ }^{[26]}$ 发现,西班牙煤炭业的全要素生产率下降了 $1.3 \%$; 王克强等 ${ }^{[27]}$ 则发现,忽略资源耗减因素,会导 致中国能源产业的全要素生产率被低估。而本文 不仅考虑了环境负外部性, 还特别考虑了资源耗竭 性以及由此带来的代际负外部性成本, 可以更为准 确地衡量采矿业的绿色全要素生产率。

在研究方法上, 全要素生产率的测度方法还在 不断发展之中。基于不同研究对象和样本数据的 特点,常用方法包括增长核算法和生产前沿面法, 其中, 增长核算法是以经济增长模型为基础, 在索 洛余值法上发展而来的, 适用于各种样本数据类 型, 但在投人要素数据的加总和处理上存在争议。生 产前沿面法分为确定性生产前沿模型法和随机前 沿生产函数法, 并逐渐演化出数据包络法 (DEA)、 Malmquist 指数法和随机前沿法 (SFA) 等。DEA 方 法通过对决策单元的投人产出指标进行评价, 可以 不用估计具体生产函数及其所涉及的参数, 即可确 定相对有效的生产前沿面, 因而适用于多投人多产 出的研究, 具有广泛的应用性。然而, 其效率的计 算容易产生测量误差, 再加上遗漏变量问题, 会对 前沿面的确定产生较大影响, 导致结果偏移。与 DEA 的基本思路类似, SFA 估计生产边界的方法是 由 Aigner 等 ${ }^{[28}$ 基于 Afriat ${ }^{[29]}$ 提出的确定性生产前沿 改进而来,该方法考虑了随机误差对经济增长的影 响, 提高了结果的准确性, 但需要收集大量样本以 及定义生产函数的具体形式。Malmquist 指数法是 在生产前沿面基础上, 将相对效率转化为距离函 数 ${ }^{[30]}$, 并通过 DEA 和 SFA 等方法加以测算, 已经广 泛用于全要素生产率研究。近年来, 将 DEA 与 Malmquist 指数相结合的方法能够实现全要素生产 率的分解, 使研究结果更准确, 且操作简单, 因而得 到广泛应用 ${ }^{[31-36]}$ 。

索洛余值法对全要素生产率的估计主要来自 生产函数。然而, 基于生产函数的估计往往无法反 映投人品价格的变化,其结果是技术最优而非经济 最优。同时,DEA 方法与 Malmquist 指数法是对投 人产出比相对效率的衡量, 对子效率指标的分解也 是基于不同参照技术的假定, 忽略了投人产出要素 本身特征对生产率的影响。Solminiha 等 ${ }^{[37}$ 针对铜矿 开采的研究证实,全要素生产率还受到矿物特征、 价格以及能源使用成本等因素的影响。同时, 以上
型。而 Rodriguez 等 ${ }^{[26]}$ 在成本函数框架下构建了修 正的索洛余值模型,既能兼顾投人要素本身特征的 影响, 又能更好地控制模型中“相关变量遗漏”问题 ${ }^{[38]}$ 因此,本文基于 Rodriguez 等 ${ }^{[26]}$ 超越对数成本函数的 修正索洛余值模型, 并借鉴 Topp 等 ${ }^{[39]}$ 、Simon 等 ${ }^{[40]}$ 王克强等 ${ }^{[27]}$ 的研究,引人双重负外部性成本, 构建采 矿业的绿色全要素生产率模型。

\section{3 考虑双重负外部性的绿色全要素生 产率模型}

本文的绿色全要素生产率 $($ GTFP) 模型构建是 在 Rodriguez 等 ${ }^{[26]}$ 、Topp 等 ${ }^{\left[{ }^{[3]}\right.} 、$ Simon 等 ${ }^{[40]}$ 以及王克强 等 ${ }^{[27]}$ 以成本函数为测度的基础模型上,将环境负外 部性成本和代际负外部性成本纳人模型, 并综合考 虑技术进步、规模报酬等因素对 GTFP 增长的影 响。在给出了测度模型的基础上,得到超越对数成 本函数的具体形式, 从而得到后文实证分析中的待 估计参数表达式。

\section{1 基于成本函数的全要素生产率分析框架}

假设采矿业生产函数形式为:

$$
Y=Y\left(X_{K}, X_{L}, t\right)
$$

式中: $Y$ 为资源产出量; $X_{K}, X_{L}$ 为资本和劳动力要素 投人量; $t$ 为时间变量。

假设企业生产遵循成本最小化原则, 则生产函 数式 (1)对应的成本函数可表示为:

$$
C=C\left(w_{K}, w_{L}, Y, t\right)
$$

式中: $w_{K}, w_{L}$ 分别为资本和劳动力的价格。

由于采矿业为资本密集性行业, 资本投人量大 且周期较长, 短期内, 在技术不变条件下, 企业资本 为不变成本, 假设 $X_{K}$ 是给定的; 劳动力 $X_{L}$ 为可变成 本。另外,环境负外部性成本和代际负外部性成本 均与矿产资源开采量有关,开采量越多,负外部性 成本越高。而且,由于两者的性质截然不同,具有 完全可分性。因此,双重负外部性成本可以分别被 视为可变成本的组成部分。那么,式(2)可改写为:

$$
\begin{aligned}
& C=V C\left(w_{L}, U C, C E, Y, t\right)+w_{K} X_{K} \\
&=\operatorname{Min}\left(w_{L} X_{L}, U C, C E\right)+w_{K} X_{K} \\
& \text { s.t. } Y=Y\left(X_{k}, X_{L}, t\right), \text { and } X_{K} \text { given }
\end{aligned}
$$

式中: $V C$ 为可变成本; $U C$ 和 $C E$ 分别为代际负外部 性成本和环境负外部性成本。 
3.1.1 考虑双重负外部性的绿色全要素生产率增 长率

根据全要素生产率的定义,其增长可表示为产 出增长中未被全部要素投人增长所解释的部分, 用 $\widehat{T F P}$ 表示 $T F P$ 的增长率,则有：

$$
\widehat{T F P}=\hat{Y}-\hat{F}
$$

式中: $\hat{Y}$ 和 $\hat{F}$ 分别为产出和全部要素投人的增长 率。因而:

$$
\hat{F}=\sum_{i=L, K} \frac{w_{i} X_{i}}{C} \times \widehat{X}_{i}=\sum_{i=L, K} S_{i} \times \widehat{X}_{i}
$$

式中: 用 $S_{i}$ 表示要素 $i$ 的成本在总成本中的比重, 即 $S_{i}=\frac{w_{i} X_{i}}{C}$ 。

根据成本函数:

$$
C=\sum_{i=L, K} w_{i} X_{i}
$$

可以得到:

$$
\begin{aligned}
\hat{C} & =\frac{\frac{\partial C}{\partial t}}{C}=\sum \frac{w_{i} X_{i}}{C} \times \frac{\partial w_{i} / w_{i}}{\partial t}+\sum \frac{w_{i} X_{i}}{C} \times \frac{\partial X_{i} / X_{i}}{\partial t} \\
& =\sum S_{i} \times \widehat{w}_{i}+\sum S_{i} \times \widehat{X}_{i}=\sum S_{i} \times \widehat{w}_{i}+\hat{F}
\end{aligned}
$$

因此:

$$
\hat{F}=\hat{C}-\sum_{i=L, K} \frac{w_{i} X_{i}}{C} \times \widehat{w}_{i}
$$

结合(4)式得到:

$$
\widehat{T F P}=\hat{Y}-\hat{C}+\sum_{i=L, K} \frac{w_{i} X_{i}}{C} \times \widehat{w}_{i}
$$

根据 (3)式, 总成本的增长率为:

$$
\begin{aligned}
\hat{C}=\frac{\frac{\partial C}{\partial t}}{C}= & \sum_{i=L, K} \frac{w_{i} X_{i}}{c} \times \hat{w}_{i}+\frac{V C}{C} \times \frac{\partial \ln V C}{\partial \ln U C} \times \widehat{U C}+ \\
& \frac{V C}{C} \times \frac{\partial \ln V C}{\partial \ln C E} \times \widehat{C E}+\frac{V C}{C} \times \frac{\partial \ln V C}{\partial \ln Y} \times \\
& \hat{Y}+\frac{X_{K}}{C} \times \frac{\partial V C}{\partial X_{k}} \times \widehat{X_{K}}+\frac{V C}{C} \times \frac{\partial \ln V C}{\partial t}+ \\
& w_{K} \times \frac{X_{k}}{C} \times \widehat{X_{k}} \\
\text { 令 } w_{K}^{*}= & -\frac{\partial V C}{\partial X_{K}}, \text { 简化起见, 设 } w_{K}=w_{K}^{*}
\end{aligned}
$$

绿色全要素生产率的增长率为:

$$
\begin{aligned}
\widehat{G T F P}= & \hat{Y}-\hat{C}+\sum \frac{\omega_{i} X_{i}}{C} \times \widehat{w}_{i} \\
= & \hat{Y}\left(1-\frac{V C}{C} \times \frac{\partial \ln V C}{\partial \ln Y}\right)-\frac{V C}{C} \times \\
& \frac{\partial \ln V C}{\partial t}-\frac{V C}{C} \times \frac{\partial \ln V C}{\partial \ln U C} \times \\
& \widehat{U C}-\frac{V C}{C} \times \frac{\partial \ln V C}{\partial \ln C E} \times \widehat{C E}
\end{aligned}
$$

式中: $\frac{V C}{C} \times \frac{\partial \ln V C}{\partial \ln Y}$ 表示可变成本的产出弹性; $-\frac{V C}{C} \times \frac{\partial \ln V C}{\partial t}$ 为成本函数随时间的变化程度, 通常 用来代表技术进步; $\frac{V C}{C} \times \frac{\partial \ln V C}{\partial \ln U C}$ 表示成本 - 代际 弹性系数, $\frac{V C}{C} \times \frac{\partial \ln V C}{\partial \ln C E}$ 表示成本 - 环境弹性系数, 分别为单位代际负外部性成本和单位环境负外部 性成本变动百分比导致的成本变动百分比。

考虑到资本投人产出的滞后性问题,在实证中 用滞后 $\tau$ 期的资本数据来计算对应的成本函数,从而 得到相应的 GTFP 增长率。

3.1.2 考虑双重负外部性的绿色全要素生产率实证 模型设定

实证模型中,超越对数函数通常更加灵活, 更 容易体现成本变化的影响,符合本文的研究目的。 因此, 本文采用超越对数函数作为成本函数形式, 因假设资本为准不变成本, 所以无 $\ln X_{K}$ 与 $t$ 的交互 项。对应的超越对数形式的成本函数为:

$\ln V C=\beta_{0}+\ln w_{L}+\beta_{Y} \ln Y+\beta_{K} \ln X_{K}+$

$$
\begin{aligned}
& \beta_{U C} \ln U C+\beta_{C E} \ln C E+\beta_{t} t+ \\
& \frac{1}{2}\left(\beta_{Y Y}(\ln Y)^{2}+\beta_{K K}\left(\ln X_{K}\right)^{2}+\right. \\
& \left.\beta_{U U}(\ln U C)^{2}+\beta_{E E}(\ln C E)^{2}+\beta_{t t} t^{2}\right)+ \\
& \beta_{K U}\left(\ln X_{K} \times \ln U C\right)+\beta_{K E}\left(\ln X_{K} \times \ln C E\right)+ \\
& \beta_{U E}(\ln U C \times \ln C E)+\beta_{Y t}(\ln Y \times t)+ \\
& \beta_{U t}(\ln U C \times t)+\beta_{E t}(\ln C E \times t)
\end{aligned}
$$

式中: $\beta_{0}$ 为常数系数; $\beta_{i}(i=L, K, U C, C E, t)$ 以及 $\beta_{i j}(i$, $j=L, K, U C, C E, t)$ 分别表示劳动、资金、代际负外部性 成本、环境负外部性成本和时间变量的影响系数, 以及不同变量的交互项系数。根据微观经济理论 中可变函数对可变要素的要求, 即 :

$$
\beta_{L}=1, \beta_{L L}=0, \beta_{K L}=0, \beta L Y=0, \beta L K=0, \beta L t=0
$$

并设 $\gamma=\frac{V C}{C}$, 因而, 绿色全要素生产率表达 式为:

$$
\begin{aligned}
\widehat{G T F P} & =\hat{Y}\left(1-\gamma\left(\beta_{Y}+\beta_{Y Y} \ln Y+\beta_{Y K} \ln X_{K}+\right.\right. \\
& \left.\left.\beta_{Y U} \ln U C+\beta_{Y E} \ln C E+\beta_{Y t} t\right)\right)- \\
& \gamma\left(\beta_{t}+\beta_{t t} t+\beta_{Y t} \ln Y+\beta_{U t} \ln U C+\beta_{E t} \ln C E\right)- \\
& \gamma\left(\beta_{U C}+\beta_{U U} \ln U C+\beta_{Y U} \ln Y+\beta_{K U} \ln X_{K}+\right. \\
& \left.\beta_{U t} t+\beta_{U E} \ln C E\right) \times \widehat{U C}-\gamma\left(\beta_{C E}+\beta_{E E} \ln C E+\right. \\
& \left.\beta_{Y E} \ln Y+\beta_{K E} \ln X_{K}+\beta_{E t} t+\beta_{U E} \ln U C\right) \times \widehat{C E}
\end{aligned}
$$


综上所述, 模型参数的含义由表 1 汇总。

\section{2 绿色全要素生产率的影响因素分解模型及估计 表达式}

根据式 (10) 和式 (11), 总成本增长率 $\hat{C}$ 与劳 动、资本、代际负外部性和环境负外部性等因素的 产出弹性有关。令 $\varepsilon_{C Y}=\frac{\partial C / C}{\partial Y / Y}$ 为成本的产出弹性, 即单位总成本变化引起产出的变化程度, 其倒数可 用来衡量规模报酬 $R S$ :

$$
\begin{gathered}
R S=\frac{\partial \ln Y}{\partial \ln C}=\frac{1}{\varepsilon_{C Y}} \\
\varepsilon_{C Y}=\frac{\partial \ln C}{\partial \ln Y}=\frac{V C}{C} \times \frac{\partial \ln V C}{\partial \ln Y}=\frac{1}{R S}
\end{gathered}
$$

这与式 (13)的 $\widehat{G T F P}$ 估算式中的第一部分相对 应, 即规模报酬。当 $R S<1$ 时, 表明规模成本递减即 规模报酬递增; $R S=1$ 和 $R S>1$ 则分别表示规模报 酬不变和递减。

同时, 式 (13) 的第二部分为成本函数随时间的 变化情况, 可以用来表征纯技术进步水平的增长 率, 即基于成本函数的技术进步率 $\widehat{T P}$ 的对偶测度 结果:

$$
\widehat{T P}=-\frac{V C}{C} \times \frac{\partial \ln V C}{\partial t}=-\frac{\partial V C / \partial t}{C}
$$

此外, 令 $U 、 E$ 分别表示成本 - 代际弹性系数和 成本-环境弹性系数,则分别有:

$$
\begin{gathered}
U=\frac{\partial C / C}{\partial U C / U C}=\frac{\partial \ln C}{\partial \ln U C}=\frac{V C}{C} \times \frac{\partial \ln V C}{\partial \ln U C} \\
E=\frac{\partial C / C}{\partial C E / C E}=\frac{\partial \ln C}{\partial \ln C E}=\frac{V C}{C} \times \frac{\partial \ln V C}{\partial \ln C E}
\end{gathered}
$$

因此,结合式(4)-(13)和式(15)-(17), 可以对 $G T F P$ 进行分解得到 $\widehat{G T F P}$ 与技术进步、规模报酬、 代际负外部性、环境负外部性等因素关系的分解表 达式如下：

$$
\begin{aligned}
\widehat{T F P} & =\hat{Y} \times\left(1-\frac{1}{R S}\right)+\widehat{T P}-U \times \widehat{U C}-E \times \widehat{C E} \\
& \cong I_{1}+I_{2}+I_{3}+I_{4}
\end{aligned}
$$

式中: $I_{1}=\hat{Y} \times\left(1-\frac{1}{R S}\right) 、 I_{2}=\widehat{T P} 、 I_{3}=-U \times \widehat{U C} 、 I_{4}=$ $-E \times \widehat{C E} ; I_{1}$ 中包含规模报酬 $R S$ 和产出因素, $R S$ 与 $G T F P$ 同方向变化,即规模报酬递增有助于 GTFP 增 长, 且 $I_{1}$ 与 $G T F P$ 变化同方向。 $I_{2}$ 揭示了 $G T F P$ 中 纯技术进步的影响,与 GTFP 变化方向一致。 $I_{3}$ 对 GTFP 的影响取决于代际负外部性成本的变动, 因 为成本 - 代际弹性系数为正 $(U>0)$, 即随着资源耗 减, 储量越小, 代际负外部性成本越高, 从而带动可 变成本的提升,因此, $I_{3}$ 的符号取决于 $\widehat{U C}$ 的符号。 同理, $I_{4}$ 的符号取决于 $\widehat{C E}$ 的符号, 环境负外部性成 本变化越大,对绿色全要素生产率的影响越大。

结合公式 (14) 和 $\gamma=\frac{V C}{C}$, 可得规模报酬的估 计式:

$$
\begin{aligned}
\frac{1}{R S}= & \gamma\left(\beta_{Y}+\beta_{Y Y} \ln Y+\beta_{Y K} \ln X_{K}+\beta_{Y U} \ln U C+\right. \\
& \left.\beta_{Y E} \ln C E+\beta_{Y t} t\right)
\end{aligned}
$$

技术进步项的估计式:

$$
\begin{gathered}
I_{2}=\widehat{T P}=-\gamma\left(\beta_{t}+\beta_{t t} t+\beta_{Y t} \ln Y+\right. \\
\left.\beta_{U t} \ln U C+\beta_{E t} \ln C E\right)
\end{gathered}
$$

代际负外部性项的估计式:

$$
\begin{gathered}
I_{3}=-U \times \widehat{U C}=-\gamma\left(\beta_{U C}+\beta_{U U} \ln U C+\beta_{Y U} \ln Y+\right. \\
\left.\beta_{K U} \ln X_{K}+\beta_{U t} t+\beta_{U E} \ln C E\right) \times \widehat{U C}
\end{gathered}
$$

环境负外部性项的估计式:

$$
\begin{gathered}
I_{4}=-E \times \widehat{C E}=-\gamma\left(\beta_{C E}+\beta_{E E} \ln C E+\beta_{Y E} \ln Y+\right. \\
\left.\beta_{K E} \ln X_{K}+\beta_{E t} t+\beta_{U E} \ln U C\right) \times \widehat{C E}
\end{gathered}
$$

最后,得到绿色全要素生产率的估计式:

表 1 模型参数的含义

Table 1 Description of parameters in the model

\begin{tabular}{cl||cl}
\hline 参数符号 & \multicolumn{1}{c||}{ 含义 } & 参数符号 & \multicolumn{1}{c}{ 含义 } \\
\hline$Y$ & 资源产出量 & $U C$ & 代际负外部性成本 \\
$X_{K}$ & 资本投人量 & $C E$ & 环境负外部性成本 \\
$X_{L}$ & 劳动投人量 & $\widehat{G T F P}$ & 绿色全要素生产率增长率 \\
$t$ & 时间变量 & $\hat{Y}$ & 产出增长率 \\
$w_{K}$ & 资本价格 & $\hat{C}$ & 成本增长率 \\
$w_{L}$ & 劳动力价格 & $\hat{F}$ & 投人要素增长率 \\
$\gamma$ & 可变成本占总成本比重 & $S_{i}$ & 要素成本占总成本比重 \\
\hline
\end{tabular}




$$
\begin{aligned}
\widehat{T F P}= & I_{1}+I_{2}+I_{3}+I_{4} \\
= & \hat{Y} \times\left(1-\gamma\left(\beta_{Y}+\beta_{Y Y} \ln Y+\beta_{Y K} \ln X_{K}+\right.\right. \\
& \left.\left.\beta_{Y U} \ln U C+\beta_{Y E} \ln C E+\beta_{Y t} t\right)\right)- \\
& \gamma\left(\beta_{t}+\beta_{t t} t+\beta_{Y t} \ln Y+\beta_{U t} \ln U C+\beta_{E t} \ln C E\right)-(23) \\
& \gamma\left(\beta_{U C}+\beta_{U U} \ln U C+\beta_{Y U} \ln Y+\beta_{K U} \ln X_{K}+\right. \\
& \left.\beta_{U t} t+\beta_{U E} \ln C E\right) \times \widehat{U C}-\gamma\left(\beta_{C E}+\beta_{E E} \ln C E+\right. \\
& \left.\beta_{Y E} \ln Y+\beta_{K E} \ln X_{K}+\beta_{E t} t+\beta_{U E} \ln U C\right) \times \widehat{C E}
\end{aligned}
$$

\section{4 变量选择与数据处理}

双重负外部性成本是本文研究所需的重要变 量, 因此,本部分首先测算双重负外部性成本,然后对 实证分析中涉及的主要变量、数据来源和处理进行 说明。

\section{1 双重负外部性成本的核算}

基于资源耗减理论,代际负外部性的核算方法 包括净价值法、净租金法、使用者成本法、净现值 法、交易价格法、替代成本法和持续价格法等 ${ }^{[4]}$ 。由 于使用者成本法不含边际成本参数, 也不要求资源 租金增长率与利率相等, 因而, 应用较为广泛。本 文选用使用者成本法对采矿业的代际负外部性成 本进行核算。该方法的核心理念是将有限期内开 采的可耗竭资源所得收人进行无限期的投资, 每年 得到永续的真实收人用于补偿资源耗竭带来的负 外部性成本。

对于某种给定资源, 假设资源的真实收人 $X$ 为 当期开采的资源经过代际间投资获得的全部收人， $T$ 为资源的开采年限,资源名义收人 $Z$ 为资源当期 的毛收人,用销售收人与销售成本的差额表示。当 真实收人的永久贴现值与耗竭资源的名义收人贴 现值相等时,则不存在资源分配的代际不公平; 当 真实收人的贴现值低于耗竭资源的名义收人贴现 值时, 则会产生代际损失。此时, 代际负外部性成
本 $U C$ 可以表示为:

$$
U C=Z-X=\frac{Z}{(1+r)^{T}}
$$

式中: $r$ 为贴现率, 参考李国平等 ${ }^{[42]}$ 选用一年期存款 利率; 各资源行业剩余可开采年限 $T$ 根据该行业主 要矿产品平均可开采年限估算而来。具体地, 煤炭 和铁矿石的开采年限分别代表煤炭开采业和黑色 金属开采业;油气开采年限以石油和天然气的可开 采年限平均值计算得到; 以铜矿、铅矿和锌矿的开 采年限平均值代表有色金属开采业 (表2)。

关于环境负外部性成本的核算,包括环境价值 损失法、条件价值估值法等 ${ }^{[33]}$ 。目前国内外学者多 使用条件价值估值法。该方法是在假想的市场条 件下,直接调查和询问人们对于环境改善的最大支 付意愿,或者对于环境损失的最小受偿意愿, 并通 过计算得来。由于中国各省市资源种类差异较大, 并且各采矿业包含的资源种类数量也不尽相同,很 难采用统一的计算方法获得环境负外部性成本。 鉴于数据可得性和计算的差异性,本文直接使用郭江 等 ${ }^{[4]}$ 、吴文洁等 ${ }^{[45]}$ 、周吉光等 ${ }^{[46]}$ 、贾舒涃等 ${ }^{[47]}$ 对采矿企 业的环境损失测算结果,即中国煤炭开采业的平均 环境损失率约为 88.68 元 $/ \mathrm{t}$, 石油开采业约为 120 元 $/ \mathrm{t}$, 天然气开采业约为 0.02 元 $/ \mathrm{m}^{3}$,黑色金属开采业约为 51.12 元 $/ \mathrm{t}$, 有色金属开采业约为 2754.70 元/ $\mathrm{t}$, 非金 属开采业约为产值的 $6.2 \%$ 。考虑到若使用产值相 关比例作为环境负外部性成本, 可能会与模型中原 有的销售产值变量存在完全相关性,所以本文只选 用与产量的相关比例进行核算。此外,黑色金属开 采业和有色金属开采业仅有 2007-2015 年和 2005-2014 年产量数据。各采矿业的环境负外部 性成本 $C E$ 可表示为 $C E=R E P \times Q$, 其中, $R E P$ 为平 均环境损失率, $Q$ 为产量。表 3 给出了环境负外部

表2 2005-2015年各类资源的可开采年限

Table 2 Residual recoverable years of each industry, 2005-2015

\begin{tabular}{lrrrrrrrrrrr}
\hline \multicolumn{1}{c}{ 行业 } & \multicolumn{1}{c}{2005} & \multicolumn{1}{c}{2006} & \multicolumn{1}{c}{2007} & \multicolumn{1}{c}{2008} & \multicolumn{1}{c}{2009} & \multicolumn{1}{c}{2010} & 2011 & 2012 & 2013 & 2014 & 2015 \\
\hline 煤炭开采业 & 180.900 & 169.980 & 159.620 & 146.820 & 137.040 & 96.574 & 67.631 & 73.106 & 77.218 & 83.866 & 91.622 \\
油气开采业 & 35.599 & 33.179 & 30.600 & 29.599 & 29.799 & 27.941 & 27.834 & 28.503 & 27.961 & 27.116 & 29.011 \\
黑色金属开采业 & 61.729 & 52.062 & 44.990 & 42.307 & 46.416 & 32.997 & 21.919 & 26.715 & 27.444 & 33.044 & 39.582 \\
有色金属开采业 & 22.155 & 20.063 & 18.381 & 16.456 & 16.051 & 13.240 & 14.240 & 10.125 & 9.826 & 10.256 & 10.804 \\
非金属开采业 & 150.380 & 138.750 & 132.300 & 152.730 & 157.430 & 142.440 & 105.580 & 100.050 & 105.470 & 106.330 & 104.600 \\
\hline
\end{tabular}


表 3 环境负外部性成本描述性统计

Table 3 Descriptive statistics of environmental negative externalities

\begin{tabular}{|c|c|c|c|c|}
\hline 行业 & 平均值 & 标准差 & 最小值 & 最大值 \\
\hline 煤炭开采业 & 253523.4 & 642263.9 & 0 & 4148007 \\
\hline 油气开采业 & 357241.6 & 749630.1 & 0 & 4408512 \\
\hline 黑色金属开采业 & 501811.7 & 1275967.0 & 5334.883 & 7649219 \\
\hline 有色金属开采业 & 614085.7 & 1568531.0 & 212.663 & $1.22 \mathrm{e}+7$ \\
\hline 非金属开采业 & 121315.9 & 321022.6 & 1726.093 & 2419624 \\
\hline
\end{tabular}

性的描述性统计。

\section{2 变量选择与数据来源}

本文的绿色全要素生产率模型主要涉及以下 变量: 第一,劳动力成本, 用工资总额作为代理指 标, 通过各地区对应行业的从业人员年末数与平减 后的真实工资相乘得到;第二,资本的使用成本,其 中,资本价格采用资本的真实利率, 即平减的中国 人民银行公布的 5 年以上贷款基准利率; 资本投人 量为平减的固定资产净值年均余额;第三,产出变 量选择平减后的工业销售产值; 第四, 代际负外部 性成本, 根据式(24)的使用者成本法进行核算, 将 各地区对应行业的营业收人减去营业成本作为当 期的毛收人。选取各采矿子行业的主要矿种,将对 应矿产资源的基础储量除以开采量作为该矿产资 源的开采年限,通过加权平均计算出该行业的开采 年限。考虑到资源可以跨省流通交易, 所以假设同 一年各地区同一开采子行业的开采年限相同,但开 采年限的变化, 取决于该年的开采数量和基础储 量; 第五, 环境负外部性成本, 通过平均环境损失率 和该地区对应矿种产量计算得到,其中,平均资源 损失率根据相关文献结论确定。在产量方面,除了 煤炭开采量直接对应煤炭开采业的产量外, 黑色金 属开采业产量由铁矿石开采量作为代理变量, 有色 金属开采业产量由《有色金属工业“十二五”发展规 划》中规定的 10 种重要的有色金属开采量作为代理 变量 ${ }^{(1)}$ 。由于石油和天然气对应的平均损失率不 同,将开采量分别乘以对应的损失率并求和。由于 超越对数函数的形式可能导致估计模型出现多重 共线性问题,因此将上述变量进行中心化处理。

本文数据主要来源于 2003-2017年的《中国统 计年鉴》《中国工业经济年鉴》《中国城市 (镇)生活
与价格年鉴》《中国有色金属年鉴》《中国能源年鉴》 《中国国土资源统计年鉴》、中国矿权资源网以及 《中国劳动统计年鉴》等。由于 2005 年的《中国工业 经济年鉴》缺失,所以, 2004 年相关数据为 2003 年和 2005 年数据平均得到。

采矿业在各省的分布不均衡, 因此, 对样本的 选择需考虑各地产业规模和数据统计情况。考虑数 据可得性,本文不包含港、澳、台地区。同时,为保持 数据的连续性和可得性, 各行业样本范围如下: (1)煤 炭开采和洗选业:剔除天津、上海、浙江、海南、广东 和西藏,共有 25 个省级样本; (2)石油与天然气开采 业: 剔除北京、山西、上海、浙江、安徽、福建、江西、 湖南、广东、广西、海南、重庆、贵州、云南、西藏和宁 夏,共有 15 个省级样本; (3)黑色金属开采业:剔除天 津、黑龙江、上海、重庆、贵州、西藏、甘肃、青海和宁 夏,共有 22 个省级样本; (4)有色金属开采业: 考虑了 剔除北京、天津、上海、江苏、海南、重庆、西藏和宁 夏后的 23 个省级样本; (5)非金属开采业:考虑了剔 除北京、天津、山西、上海、海南、西藏、宁夏和新疆 后的 23 个省级样本。由于非金属开采业的各省资 源产量数据不可得, 本文不作讨论。

\section{5 结果与分析}

本部分内容将在模型设定与样本数据基础上, 选择合适的面板数据模型进行参数估计。并在估 计了考虑双重负外部性的采矿业绿色全要素生产 率后, 分解绿色全要素生产率, 最后采用修正索洛 余值模型,估计煤炭、油气、黑色金属和有色金属 4 个子采矿业的全要素生产率并进行对比,深人分析 双重负外部性成本对采矿业绿色全要素生产率的 影响。

(1) 10 种有色金属具体指铜、铝、铅、锌、镍、锡、锑、镁、海绵钛和录。 


\section{1 面板模型估计方法的选择}

常用的面板数据估计方法包括混合最小二乘 回归法、固定效应模型法和随机效应模型法等, 一 般通过 $\mathrm{F}$ 检验、BP 检验和 Hausman 检验等方法进行 篮选。此外,这些估计方法通常存在同方差、不存 在序列相关性等强假设,但现实中各地区的采矿业 可能因地质条件、技术水平等差异导致各省之间存 在异方差，而各地区间的贸易往来和技术溢出又容易 产生误差自相关问题。因此, 需要进一步对残差进 行异方差检验和自相关检验。经检验 (表 4), 面板 数据存在异方差和误差自相关问题。常见的可同 时控制异方差和自相关的方法有可行广义最小二 乘法 (FGLS) 和面板校正法 (PCSE)。鉴于 PCSE 方 法在样本数据较少时仍能够得到较为稳健的参数 估计结果, 因而,本文采用PCSE对模型进行估计。

\section{2 模型系数估计、绿色全要素生产率计算与分解}

5.2.1 成本函数模型的系数估计

首先, 采用上面选择的面板模型估计方法, 计 算得到 4 个采矿业子行业关于成本函数模型式(12) 的系数(表 5$)$ 。

从表 5 可以看出, 4 个子行业模型参数联合检验 都显著不为 0 , 且从 coldiag $^{2}$ 系数来看, 存在共线性 问题。但是, 由于本文选用的是面板数据, 样本量 相对充足, 并对变量进行了中心化处理,共线性问 题仍在可接受范围。

从估计系数来看, 各系数符号不完全一致, 可 以很好地反映采矿业的共性以及各子行业的异质 性。单个因素系数结果显示, $\beta_{Y} 、 \beta_{K}$ 的符号皆为 正, 且通过显著性检验, 表明要素投人带动规模扩 大会增加可变成本,符合预期。在有色金属开采业 和油气开采业,表征时间趋势的 $\beta_{t}$ 显著为负, 即在 控制其他要素的情况下, 劳动报酬随时间逐步下 降, 说明这两个行业在样本期间均有显著的生产效
率增长。而煤炭和黑色金属色开采业的 $\beta$, 显著为 正,与该行业人均工资在样本区间明显提升有关。 在 4 个行业中,平方项 $\beta_{K K}$ 和 $\beta_{Y Y}$ 基本都显著, 且符 号一致，说明随着产出的增大、资本投人的扩大以 及人力资源的结构性提升导致整体薪酬上升,对可 变成本的边际影响增加, 这反映了采矿业规模的快 速扩张。煤炭开采业和黑色金属开采业的 $\beta_{t t}$ 系数 显著为负,说明随着时间的推移,工资上涨的影响 减弱,生产效率的改进效应逐渐显现。从交互项来 看, 黑色金属开采业 $\beta_{Y K}$ 显著为负, 煤炭、油气资源 和黑色金属开采业 $\beta_{Y t}$ 均显著为负，说明资本投人 越多、技术水平越高, 相应的产出对可变成本的边 际影响越小; 而油气开采业的 $\beta_{Y K}$ 交互项显著为正, 说明资本对产出的边际成本影响是正向的。

从反映双重负外部性的 $U C$ 和 $C E$ 及其相关项 系数来看,显著项系数整体一致,表明采矿业的代 际负外部性和环境负外部性具有相同的特性。从 单个因素系数来看, $\beta_{U C} 、 \beta_{C E}$ 符号皆为正,表明双 重负外部性成本的增加会带动可变成本的增加, 符 合预期。而其平方项 $\beta_{U U}$ 和 $\beta_{E E}$ 显著为正, 表明双 重负外部性对可变成本的边际影响有所增加。煤 炭开采业的 $\beta_{K U}$, 煤炭开采业、油气开采业以及黑色 金属开采业的 $\beta_{K E}$ 均为负, 说明资本的投人可能带 来机械化水平的提升,开采设备的更新换代降低了 负外部性成本对可变成本的边际影响。但是, 有色 金属开采业的 $\beta_{K U}$ 则显著为正,说明该行业的资本 扩张会加剧代际负外部性对可变成本的边际影 响。从产出与负外部性的交互项来看, 煤炭开采业 与黑色金属开采业的 $\beta_{Y U}$ 和 $\beta_{Y E}$ 、油气开采业的 $\beta_{Y U}$ 以及有色金属开采业的 $\beta_{Y E}$ 均为负, 说明随着产出 的增加,负外部性成本对可变成本的边际影响越来 越小。而油气开采业的 $\beta_{Y E}$ 为正, 即随着产出的增

表4 估计模型的检验与选择

Table 4 Estimation model test and selection

\begin{tabular}{lllcccc}
\hline \multicolumn{1}{c}{ 检验 } & \multicolumn{1}{c}{ 检验方法 } & \multicolumn{1}{c}{ 煤炭 } & 油气 & 黑色金属 & 有色金属 & 说明 \\
\hline 混合估计还是固定效应 & $\mathrm{F}$ 检验 & $F=30.84$ & $F=16.70$ & $F=21.95$ & $F=11.28$ & 选择固定效应 \\
混合估计还是随机效应 & BP 检验 & $c h i^{2}=489.45$ & $c h i^{2}=216.05$ & $c h i^{2}=402.29$ & $c h i^{2}=171.93$ & 选择随机效应 \\
随机效应还是固定效应 & Houseman 检验 & $c h i^{2}=60.14$ & $c h i^{2}=33.43$ & $c h i^{2}=15.53$ & $c h i^{2}=31.44$ & 选择固定效应 \\
是否存在异方差 & wald检验 & $c h i^{2}=19703.67$ & $c h i^{2}=1451.69$ & $c h i^{2}=1647.38$ & $c h i^{2}=4815.33$ & 存在异方差 \\
是否存在自相关 & wooldridge & $F=41.81$ & $F=8.45$ & $F=30.50$ & $F=39.41$ & 存在自相关 \\
\hline
\end{tabular}


表 5 采矿业的模型参数估计结果

Table 5 Estimation of model parameters for each mining industry

\begin{tabular}{|c|c|c|c|c|}
\hline 估计系数 & 煤炭 & 油气 & 黑色金属 & 有色金属 \\
\hline$\beta_{Y}$ & $0.1996^{* *}$ & $0.3976^{* * *}$ & $0.8792 * *$ & $0.3815^{* *}$ \\
\hline$\beta_{K}$ & $0.6341 * * *$ & $0.2297 * * *$ & $0.3280 * * *$ & $0.0889^{*}$ \\
\hline$\beta_{U C}$ & $0.0477 * * *$ & $0.6656^{* * *}$ & $0.2708^{* *}$ & $0.2594 * * *$ \\
\hline$\beta_{C E}$ & $0.1609^{* * *}$ & 0.0140 & $0.1408^{* *}$ & $0.2741 * * *$ \\
\hline$\beta_{t}$ & 0.0120 & $-0.0097^{* *}$ & $0.0463^{*}$ & $-0.0179 * * *$ \\
\hline$\beta_{Y Y}$ & $0.1832 *$ & $0.1666^{*}$ & $0.6836^{* * *}$ & 0.0848 \\
\hline$\beta_{K K}$ & $0.0873^{* * *}$ & $0.2448 * * *$ & $0.2220 * * *$ & $0.0988^{*}$ \\
\hline$\beta_{U U}$ & $0.0211^{* *}$ & $0.1793 * * *$ & $0.2473 * * *$ & -0.1776 \\
\hline$\beta_{E E}$ & $0.1598 * * *$ & $0.0923 * * *$ & $0.1910^{* * *}$ & $0.0541 * * *$ \\
\hline$\beta_{u}$ & $-0.0227 * * *$ & -0.0001 & $-0.0202^{* * *}$ & -0.0002 \\
\hline$\beta_{Y K}$ & -0.0154 & $0.6902 * *$ & $-0.1303^{* * *}$ & -0.0372 \\
\hline$\beta_{Y U}$ & -0.0057 & $-0.1920 * * *$ & $-0.5999 * * *$ & 0.1605 \\
\hline$\beta_{Y E}$ & $-0.0955^{* *}$ & $0.1927 * * *$ & $-0.2827 * * *$ & $-0.1334 * * *$ \\
\hline$\beta_{K U}$ & $-0.0247^{*}$ & 0.0712 & 0.0835 & $0.1899^{*}$ \\
\hline$\beta_{K E}$ & $-0.1434 * * *$ & $-0.2718^{* * *}$ & $-0.2119^{* * *}$ & 0.0088 \\
\hline$\beta_{y_{t}}$ & $-0.0218 * * *$ & $-0.0223^{*}$ & $-0.1033^{* *}$ & -0.0182 \\
\hline$\beta_{U t}$ & 0.0086 & $0.0205 * *$ & 0.0485 & -0.0109 \\
\hline$\beta_{E t}$ & $0.0155^{* * *}$ & -0.0042 & 0.0243 & $0.0202 * * *$ \\
\hline$\beta_{U E}$ & -0.0091 & $-0.1918^{* * *}$ & 0.0047 & -0.0031 \\
\hline$\beta_{0}$ & $0.1877 * * *$ & $-0.0361^{*}$ & -0.0782 & $-0.1767 * * *$ \\
\hline 整体 $R^{2}$ & 0.9827 & 0.8951 & 0.8661 & 0.8767 \\
\hline Coldiag $^{2}$ & 61.57 & 63.23 & 72.13 & 93.16 \\
\hline
\end{tabular}

注: $* * * * * *$ 分别表示在 $10 \% 、 5 \% 、 1 \%$ 的水平上显著。

加,环境负外部性成本对可变成本的边际影响有所 上升。时间变量与负外部性的交互项中, 仅有油气 开采业的 $\beta_{U t}$ 、煤炭开采业和有色金属开采业的 $\beta_{E t}$ 显著, 且均为正, 说明负外部性成本对可变成本的 边际影响日益增大。 $\beta_{U E}$ 仅在油气开采业显著为 负,说明随着代际负外部性的上升,环境负外部性 的边际影响会有所下降。

\subsection{2 绿色全要素生产率的计算}

根据式(10),并结合表 5 的模型估计系数,下面 分别计算采矿业各子行业的全国平均绿色全要素 生产率的变动情况,结果参见表 6 。

整体上,采矿业各子行业在 2005-2015 年平均 绿色全要素生产率增长率均为正, 说明生产率水平 在不断提升。与陈超凡 ${ }^{[24]}$ 、赵萌 ${ }^{[25]}$ 等仅考虑环境负 外部性的研究结果不同,煤炭开采业、黑色金属开 采业和有色金属开采业的 GTFP 不仅没有下降,在 样本期间增长率甚至均超过 15\%。这与本文采用
了成本函数形式有关。煤炭开采业的发展受益于 中国经济快速增长所引致的能源需求增长, 2002年 以来动力煤价格不断攀升, 到 2011 年底煤炭价格达

表 $62005-2015$ 年采矿业各子行业 $G T F P$ 变动情况

Table 6 Growth rate of green total factor productivity (GTFP) in mining industries, 2005-2015

\begin{tabular}{ccccc}
\hline$\widehat{\text { GTFP }} / \%$ & 煤炭 & 油气 & 黑色 & 有色 \\
\hline 2005 & 30.93 & 17.20 & - & 23.37 \\
2006 & 21.08 & 12.40 & - & 32.41 \\
2007 & 19.70 & 2.43 & 33.25 & 21.85 \\
2008 & 41.36 & 2.48 & 42.57 & 10.40 \\
2009 & 16.81 & -11.62 & 11.49 & 4.88 \\
2010 & 20.38 & 14.07 & 38.17 & 25.47 \\
2011 & 22.84 & 13.52 & 21.84 & 20.54 \\
2012 & 16.16 & -6.53 & 17.38 & 10.50 \\
2013 & 10.49 & -3.74 & 18.59 & 7.34 \\
2014 & 5.91 & 0.78 & 8.68 & 3.17 \\
2015 & -2.86 & -23.78 & -8.07 & - \\
平均 & 18.44 & 1.57 & 20.43 & 15.99 \\
\hline
\end{tabular}


到了历史高位, 因此, 2005-2011年间煤炭开采业 的 GTFP 增长率平均近 $25 \%$ 。2012 年以后, 受中国 经济增速放缓和产能过剩的影响, 煤炭需求萎缩、 价格下跌, 因而 GTFP 增长率出现负值, 为 $-2.86 \%$ 。 类似的走势也发生在黑色金属开采业,但其波动幅 度更大, 主要是受到钢铁产业去产能的影响。这一 结果整体上与王克强等 ${ }^{[27]}$ 考虑能源耗减因素的研究 结论一致。但是, 由于本文对代际负外部性的考虑 不仅包括能源成本,还包括资源耗竭带来的代际成 本,因此,绿色全要素生产率的增长幅度不同。

有色金属开采业整体发展较为平缓,但在 2006 年、2009年和 2012 年分别出现拐点。2006年是在下 游需求旺盛和宽松货币政策背景下,国内外投资资金 不断进人大宗商品交易市场,引起了有色金属价格整 体大幅度上涨; 2009 年受次贷危机的影响, GTFP 增 速下降,仅为 $4.88 \%$; 而 2010 年受 4 万亿救市政策的 刺激形成了新一轮波峰,但是,随着宏观经济的放缓, GTFP 增速逐年下降。石油与天然气开采业在样本 期间虽然整体上也呈现增长趋势,但平均增长率仅为 $1.57 \%$, 远低于其他行业,这与油气的国内储量不足、 产量增长乏力有关。在 2009 年和 2015 年受石油价 格和消费量大幅下降的影响, GTFP 增长率降为负 值。而在 2010 年受当年需求拉动的影响, 并在 2009 年基数较低的情况下, 出现了大幅度上涨。然而,随
后几年, 在供给侧结构性改革的影响下,其 GTFP增 长率一直处于较低水平, 2015 年甚至低至-23.78\%。

\subsection{3 绿色全要素生产率的分解}

根据式 (23), 并结合模型估计系数表 5, 可分别 计算采矿业各子行业绿色全要素生产率的分解情 况,参见表 7-10。

(1)煤炭开采业绿色全要素生产率分解结果

从表 7 可知, 煤炭开采业的技术进步率平均达 $11.17 \%$, 在分解项中贡献最大, 这与多年来的“关停 并转”、去低端产能、提高机械化水平等政策有关。 其次是规模报酬的影响, 根据式(24), 这与销售产 值有关。销售产值的波动主要体现2008-2010年期 间,呈现先下降后提升趋势, 此后伴随着煤炭产能 过剩问题日益凸显,销售产值的增速不断下降,从 2013 年开始出现负增长。这导致规模报酬也呈现 先下降后上升的趋势。负外部性因素对 GTFP 的贡 献整体为负, 其中, 代际负外部性的平均贡献为 -2.19 , 高于环境负外部性的影响。总体来看, 资源 过度开采与粗放式利用严重影响了中国煤炭资源 的可持续发展,破坏了生态环境,产生了较高的双 重负外部性成本, 延缓了产业的绿色技术进步。相 对而言, 代际负外部性成本的影响高于环境负外部 性成本,这与中国煤炭开采业的产业政策和本文负 外部性成本计算偏差有关。中国煤炭市场价格波

表 $72005-2015$ 年煤炭开采业 $G T F P$ 平均增长及其分解情况

Table 7 Average growth rate and decomposition of green total factor productivity (GTFP) in coal mining industry, 2005-2015

\begin{tabular}{|c|c|c|c|c|c|c|c|c|c|c|c|}
\hline \multirow{3}{*}{ 年份 } & \multirow{3}{*}{$\widehat{G T F P} / \%$} & \multicolumn{10}{|c|}{$G T F P$ 分解 } \\
\hline & & \multicolumn{3}{|c|}{$I_{1}$} & \multirow{2}{*}{$\frac{I_{2}}{\widehat{T P} / \%}$} & \multicolumn{3}{|c|}{$I_{3}$} & \multicolumn{3}{|c|}{$I_{4}$} \\
\hline & & 小计 $/ \%$ & $R S$ & $\hat{Y} / \%$ & & 小计/\% & $U$ & $\widehat{U C} / \%$ & 小计 $/ \%$ & $E$ & $\widehat{C E} / \%$ \\
\hline 2005 & 30.93 & 29.22 & 4.48 & 37.61 & 5.92 & -1.08 & 0.02 & 48.43 & -3.13 & 0.17 & 18.75 \\
\hline 2006 & 21.08 & 18.83 & 4.25 & 24.36 & 7.21 & -1.56 & 0.03 & 53.97 & -3.20 & 0.18 & 18.13 \\
\hline 2007 & 19.70 & 16.01 & 4.11 & 21.17 & 8.43 & -2.31 & 0.04 & 64.54 & -2.42 & 0.18 & 13.47 \\
\hline 2008 & 41.36 & 35.25 & 3.56 & 50.38 & 9.85 & -5.52 & 0.05 & 118.38 & 0.79 & 0.16 & -4.83 \\
\hline 2009 & 16.81 & 8.98 & 3.73 & 12.26 & 10.56 & -1.02 & 0.05 & 21.64 & -1.72 & 0.16 & 10.94 \\
\hline 2010 & 20.38 & 21.44 & 3.47 & 30.14 & 11.82 & -11.32 & 0.06 & 175.80 & -1.56 & 0.16 & 9.96 \\
\hline 2011 & 22.84 & 16.81 & 3.14 & 24.64 & 13.79 & -5.80 & 0.08 & 76.15 & -1.96 & 0.17 & 11.71 \\
\hline 2012 & 16.16 & 2.89 & 3.26 & 4.16 & 14.77 & -0.91 & 0.08 & 11.86 & -0.59 & 0.16 & 3.66 \\
\hline 2013 & 10.49 & -5.11 & 3.85 & -6.90 & 14.37 & 1.69 & 0.06 & -25.43 & -0.46 & 0.15 & 3.05 \\
\hline 2014 & 5.91 & -9.18 & 4.69 & -11.67 & 13.69 & 2.00 & 0.06 & -36.13 & -0.60 & 0.13 & 4.48 \\
\hline 2015 & -2.86 & -17.79 & 6.21 & -21.21 & 12.45 & 1.70 & 0.04 & -38.41 & 0.79 & 0.11 & -6.89 \\
\hline 平均 & 18.44 & 10.74 & 4.07 & 15.00 & 11.17 & -2.19 & 0.05 & 42.80 & -1.28 & 0.16 & 7.49 \\
\hline
\end{tabular}


部性。这说明,油气资源, 特别是石油资源耗竭的 影响加剧了。

(3)黑色金属开采业绿色全要素生产率分解结果 由表 9 可知,规模报酬对黑色金属开采业的影 响最大, 因为其销售产值的变化与煤炭开采业基本 一致,但波动幅度更大; 规模报酬呈现逐年上升态 势, 与 “十二五”期间铁矿石开采业的产业集中度从 40.74\%升至 $66.15 \%$ 的现状相符合。技术进步率也 有较大的提升,因为该行业的专利申请量由 2011 年 的 90 项增加至 2016 年的 762 项, 增长了近 8.5 倍。 代际负外部性的影响高于环境负外部性,原因在 于, 中国铁矿石资源相对丰富,但品位低、贫矿多, 开采损耗严重, 而且铁矿石产量稳居世界第一,这 样的过度开采导致资源耗竭加快。黑色金属开采 业也是工业固废和废气的主要来源, 具有一定的环 境负外部性影响,但由于其成本变动幅度不大,所 以对 GTFP 的影响较弱。

(4)有色金属开采业绿色全要素生产率分解结果

由表 10 可以发现,规模报酬对有色金属开采业 的影响最大,但其整体变化不大,维持在 $4 \%$ 左右的 高水平,而销售产值的波动方向与上述分析的宏观 经济走势基本相同,但与前 3 个行业相比,波动幅度 更低且都为正增长, 原因一是与其本身基数较低有 关;二是有色金属开采业包括了多个矿产资源品 种,可以进行风险对冲。有色金属开采业的技术进

表 $82005-2015$ 年油气开采业 $G T F P$ 平均增长及其分解情况

Table 8 Average growth rate and decomposition of green total factor productivity (GTFP) in oil and gas mining industry, 2005-2015

\begin{tabular}{|c|c|c|c|c|c|c|c|c|c|c|c|}
\hline \multirow{3}{*}{ 年份 } & \multirow{3}{*}{$\widehat{G T F P} / \%$} & \multicolumn{10}{|c|}{ GTFP 分解 } \\
\hline & & \multicolumn{3}{|c|}{$I_{1}$} & \multirow{2}{*}{$\frac{I_{2}}{T P / \%}$} & \multicolumn{3}{|c|}{$I_{3}$} & \multicolumn{3}{|c|}{$I_{4}$} \\
\hline & & 小计/\% & $R S$ & $\hat{Y} / \%$ & & 小计 $/ \%$ & $U$ & $\widehat{\widehat{U C} / \%}$ & 小计 $/ \%$ & $E$ & $\widehat{C E} / \%$ \\
\hline 2005 & 17.20 & 20.97 & 3.79 & 26.02 & 0.21 & -2.04 & 0.08 & 25.00 & -0.13 & 0.04 & 3.00 \\
\hline 2006 & 12.4 & 16.44 & 3.55 & 20.70 & 0.22 & -2.52 & 0.09 & 27.30 & -0.17 & 0.05 & 3.56 \\
\hline 2007 & 2.43 & 2.04 & 3.93 & 2.52 & 0.22 & 0.19 & 0.08 & -2.31 & 0.15 & 0.04 & -3.65 \\
\hline 2008 & 2.48 & 6.45 & 3.13 & 8.43 & 0.23 & -3.40 & 0.11 & 30.60 & -0.08 & 0.05 & 1.67 \\
\hline 2009 & -11.62 & -16.62 & 3.89 & -20.65 & 0.25 & 3.47 & 0.07 & -48.36 & 0.01 & 0.03 & -0.31 \\
\hline 2010 & 14.07 & 21.26 & 3.42 & 27.18 & 0.25 & -5.11 & 0.09 & 55.35 & -0.29 & 0.04 & 8.02 \\
\hline 2011 & 13.52 & 18.32 & 3.37 & 23.43 & 0.25 & -3.20 & 0.10 & 32.33 & -0.02 & 0.04 & 0.64 \\
\hline 2012 & -6.53 & -7.99 & 3.74 & -9.97 & 0.21 & 0.62 & 0.09 & -6.68 & -0.06 & 0.03 & 2.14 \\
\hline 2013 & -3.74 & -5.21 & 3.80 & -6.50 & 0.22 & 0.85 & 0.09 & -9.84 & -0.01 & 0.03 & 0.54 \\
\hline 2014 & 0.78 & 0.87 & 4.75 & 1.01 & 0.19 & 0.37 & 0.07 & -5.66 & -0.59 & 0.02 & 28.10 \\
\hline 2015 & -23.78 & -27.92 & 6.12 & -32.00 & 0.19 & 2.49 & 0.04 & -59.82 & 0.30 & 0.01 & -21.27 \\
\hline 平均 & 1.57 & 2.60 & 3.94 & 3.65 & 0.22 & -0.75 & 0.08 & 3.45 & -0.08 & 0.03 & 2.04 \\
\hline
\end{tabular}


表9 2007-2015 年黑色金属开采业 GTFP 平均增长及其分解情况

Table 9 Average growth and decomposition of green total factor productivity (GTFP) in the ferrous metal mining industry, 2007-2015

\begin{tabular}{|c|c|c|c|c|c|c|c|c|c|c|c|}
\hline \multirow{3}{*}{ 年份 } & \multirow{3}{*}{$\widehat{G T F P} / \%$} & \multicolumn{10}{|c|}{ GTFP 分解 } \\
\hline & & \multicolumn{3}{|c|}{$I_{1}$} & \multirow{2}{*}{$\frac{I_{2}}{T P / \%}$} & \multicolumn{3}{|c|}{$I_{3}$} & \multicolumn{3}{|c|}{$I_{4}$} \\
\hline & & 小计 $/ \%$ & $R S$ & $\hat{Y} / \%$ & & 小计 $/ \%$ & $U$ & $\widehat{U C} / \%$ & 小计/\% & $E$ & $\widehat{C E} / \%$ \\
\hline 2007 & 33.20 & 33.25 & 3.70 & 46.49 & 7.36 & -6.32 & 0.11 & 56.43 & -1.71 & 0.09 & 19.46 \\
\hline 2008 & 42.57 & 44.46 & 3.32 & 63.62 & 8.63 & -9.16 & 0.12 & 75.10 & -1.35 & 0.07 & 20.74 \\
\hline 2009 & 11.49 & 0.72 & 3.60 & 1.00 & 8.68 & 2.48 & 0.08 & -29.58 & -0.40 & 0.06 & 6.95 \\
\hline 2010 & 38.17 & 41.31 & 3.89 & 55.58 & 9.04 & -11.39 & 0.11 & 104.05 & -0.79 & 0.04 & 21.59 \\
\hline 2011 & 21.84 & 18.71 & 3.73 & 25.55 & 11.06 & -7.78 & 0.15 & 50.82 & -0.16 & 0.02 & 6.72 \\
\hline 2012 & 17.38 & 5.15 & 4.10 & 6.82 & 10.94 & 1.68 & 0.13 & -13.06 & -0.40 & 0.03 & 14.52 \\
\hline 2013 & 18.59 & 8.02 & 4.58 & 10.26 & 11.31 & -0.56 & 0.13 & 4.23 & -0.18 & 0.02 & 11.28 \\
\hline 2014 & 8.68 & -3.26 & 5.92 & -3.92 & 9.53 & 2.44 & 0.09 & -26.08 & -0.04 & 0.01 & 2.67 \\
\hline 2015 & -8.07 & -20.60 & 7.58 & -23.72 & 9.15 & 3.24 & 0.08 & -39.82 & 0.13 & 0.02 & -7.69 \\
\hline 平均 & 20.43 & 14.27 & 4.49 & 20.19 & 9.52 & -2.82 & 0.11 & 20.23 & -0.55 & 0.04 & 10.69 \\
\hline
\end{tabular}

步率有一定的提升,平均水平为 $2.12 \%$ 。代际负外 部性和环境负外部性对 GTFP 的贡献整体为负, 从 弹性系数来看,成本-环境弹性系数更大。一方面, 中国有色金属矿种类较多,且多为贫矿和伴生矿 床, 品位较低,增加了开采难度和资源的综合利用, 开采中的资源浪费和环境破坏严重, 具有较高的代 际负外部性和环境负外部性;另一方面,在有色金 属开采过程中,企业更多地采用了较为落后的化学 提取方法,且耗水、耗电量巨大,这不仅是“三废”排 放的主要来源, 而且污染物中所含有的化学物质也 会进一步破坏生态环境,产生较高的环境负外部性
成本, 对 GTFP 产生较大影响。

\section{3 与修正索洛余值模型结果的对比}

为了更深人分析环境负外部性与代际负外部 性对估计结果的影响, 本文根据修正索洛余值模 型, 在不考虑双重负外部性情况下, 对以上 4 个行业 的全要素生产率进行测算,并与考虑双重负外部性 的绿色全要素生产率进行比较分析, 比较结果如图 1 所示。从图 1 中可以看出,两个模型的整体结果呈 现基本一致的发展趋势,差别主要体现在以下两 点:一是绿色全要素生产率增速普遍较低, 这是因 为负外部性成本的内部化提高了可变成本; 但在

表 102005 -2014 年有色金属开采业 GTFP 平均增长及其分解情况

Table 10 Average growth rate and decomposition of green total factor productivity (GTFP) in nonferrous metal mining industry,

2005-2014

\begin{tabular}{|c|c|c|c|c|c|c|c|c|c|c|c|}
\hline \multirow{3}{*}{ 年份 } & \multirow{3}{*}{$\widehat{G T F P} / \%$} & \multicolumn{10}{|c|}{ GTFP 分解 } \\
\hline & & \multicolumn{3}{|c|}{$I_{1}$} & \multirow{2}{*}{$\frac{I_{2}}{T P / \%}$} & \multicolumn{3}{|c|}{$I_{3}$} & \multicolumn{3}{|c|}{$I_{4}$} \\
\hline & & 小计 $\%$ & $R S$ & $\hat{Y} / \%$ & & 小计 $/ \%$ & $U$ & $\widehat{U C} / \%$ & 小计 $/ \%$ & $E$ & $\widehat{C E} / \%$ \\
\hline 2005 & 23.37 & 23.41 & 4.28 & 30.55 & 1.40 & -1.11 & 0.07 & 15.47 & -0.33 & 0.16 & 2.00 \\
\hline 2006 & 32.41 & 31.76 & 3.54 & 44.28 & 1.92 & -0.59 & 0.03 & 18.39 & -0.68 & 0.16 & 4.15 \\
\hline 2007 & 21.85 & 20.83 & 3.30 & 29.89 & 2.20 & -0.17 & 0.03 & 6.46 & -1.01 & 0.17 & 5.83 \\
\hline 2008 & 10.40 & 8.68 & 4.02 & 11.55 & 1.96 & 0.01 & 0.04 & -0.25 & -0.25 & 0.15 & 1.67 \\
\hline 2009 & 4.88 & 2.95 & 4.74 & 3.74 & 1.81 & 0.14 & 0.05 & -2.66 & -0.02 & 0.14 & 0.14 \\
\hline 2010 & 25.47 & 24.38 & 4.27 & 31.84 & 2.10 & -0.37 & 0.03 & 12.21 & -0.64 & 0.14 & 4.45 \\
\hline 2011 & 20.54 & 18.34 & 3.52 & 25.61 & 2.64 & -0.08 & 0.01 & 8.47 & -0.36 & 0.16 & 2.23 \\
\hline 2012 & 10.50 & 8.04 & 3.70 & 11.03 & 2.67 & 0.01 & 0.02 & -0.65 & -0.22 & 0.16 & 1.38 \\
\hline 2013 & 7.34 & 5.36 & 4.42 & 6.93 & 2.37 & 0.07 & 0.03 & -2.55 & -0.46 & 0.15 & 3.05 \\
\hline 2014 & 3.17 & 1.45 & 5.25 & 1.78 & 2.09 & 0.14 & 0.05 & -2.99 & -0.51 & 0.15 & 3.48 \\
\hline 平均 & 15.99 & 14.52 & 4.11 & 19.72 & 2.12 & -0.19 & 0.04 & 5.22 & -0.45 & 0.16 & 2.84 \\
\hline
\end{tabular}




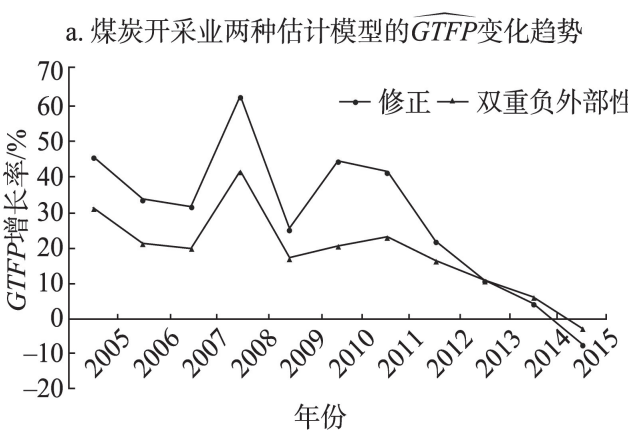

c. 黑色金属开采业两种估计模型的 $\widehat{G T F P}$ 变化趋势

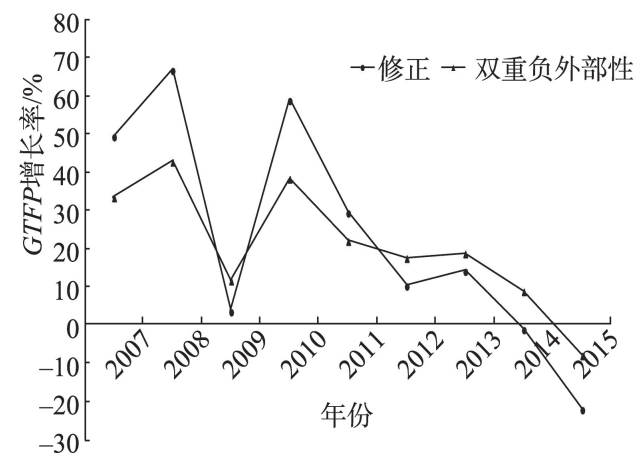

b. 油气开采业两种估计模型的 $\widehat{G T F P}$ 变化趋势

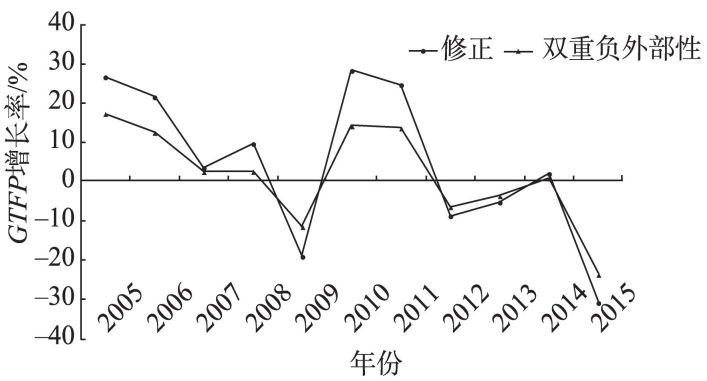

d. 有色金属开采业两种估计模型的 $\widehat{G T F P}$ 变化趋势

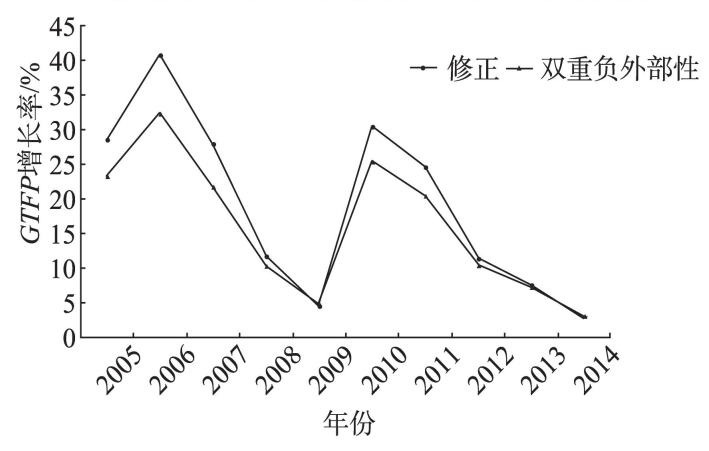

图 1 采矿业子行业双重负外部性加入前后 $\widehat{G T F P}$ 变化趋势

Figure 1 Trend of $\widehat{\text { GTFP }}$ of two estimation models for each mining industry

2014 年后出现了反超, 其中, 黑色金属开采业在 2011 年就出现了反超, 这说明负外部性的影响开始 下降; 二是绿色全要素生产率的变化趋势更为平 缓, 根据式(13) 可以发现, $\hat{Y}$ 项与 $\widehat{U C} 、 \widehat{C E}$ 项的计算 符号相反, 在计算绿色全要素生产率增速的过程 中, 产生了相互抵消效应。

\section{6 结论与政策建议}

\section{1 结论}

本文构建了考虑环境代际负外部性的绿色全 要素生产率测度模型, 并以 2005-2015 年省级面板 数据为样本, 实证研究了中国采矿业的绿色全要素 生产率变化情况和关键影响因素。主要结论如下:

第一, 基于成本函数模型的估计结果显示, 采 矿业的双重负外部性特性相同,均对行业可变成本 具有显著负向影响, 因此, 在采矿业绿色全要素生 产率计算中有必要考虑双重负外部性成本, 否则可 能导致 GTFP 估计结果产生偏误。

第二, 考虑双重负外部性的绿色全要素生产率 计算结果显示, 采矿业各子行业的绿色全要素生产 率均有显著增长。黑色金属开采业增速最为明显,
平均达到 $20.43 \%$; 其次为煤炭开采业, 平均为 $18.44 \%$; 有色金属开采业平均达到 $15.99 \%$; 而油气 开采业最低, 仅为 $1.57 \%$ 。

第三, 对绿色全要素生产率影响因素的分解发 现, 销售产值增速的影响最大, 规模报酬呈现递增 趋势。除油气开采业外,其他产业的纯技术进步增 速明显。代际负外部性和环境负外部性因素对 GTFP 皆呈现抑制作用, 但由于各子行业的资源特 性差异较大,相对而言, 煤炭开采业和有色金属开 采业受环境负外部性的影响较大,而油气开采业和 黑色金属开采业则受代际负外部性的影响更大。

第四, 两种模型估计结果的比较分析发现, 考 虑双重负外部性的绿色全要素生产率增速一般低 于不考虑负外部性成本的修正索洛余值模型的结 果, 并且变化趋势更为平稳, 这愈加验证了本文关 于双重负外部性对 GTFP 具有抑制作用的结论。

\section{2 政策建议}

根据上述研究结论, 本文提出以下 3 条政策建议:

第一,鉴于代际负外部性和环境负外部性对采 矿业各子行业绿色全要素生产率的影响存在异质 
性, 政府应制定以下差异化政策, 有针对性地缓解 不同采矿业的负外部性问题。

代际负外部性对绿色全要素生产率具有负面 影响,全行业的可持续发展将受到严重挑战。为解 决这一问题, 首先, 应提高矿产资源开发利用的技 术准人门槛, 以技术升级方式有效控制资源浪费与 能源过度消耗。例如,鼓励资源高效开采技术和高 效利用技术, 限制并淘汰落后技术与产能, 提高矿 产资源的开采效率、回采率和“三废”综合利用率; 其次, 根据各类资源的储采比制定不同的税费标准 与贸易政策。对于受代际负外部性影响程度较高 的油气资源和黑色金属矿产, 比如石油、铁和铜等, 其价格的上涨可能导致成本驱动型通货膨胀, 因 此, 可考虑免征进口税或实施即征即退的优惠政 策; 对于锰、铬、铝等非战略性矿产品, 可考虑实施 进口税率减半等优惠政策, 以平衡国内外资源供给 与需求的矛盾, 减缓资源耗竭的压力; 而对于储量 较为丰富的资源, 则要建立产量与耗竭状况的预警 机制, 防止过度开采与压价出口。总体来说, 就是 通过鼓励进口、限制出口等方式缩小国内供需缺 口, 降低代际负外部性对绿色全要素生产率的制约 作用,保持采矿业绿色技术进步的增长趋势。

环境负外部性对绿色全要素生产率具有明显 的抑制作用。为解决这一问题, 首先, 政府应明确 矿山企业在环境保护、土地复垦、植被恢复等方面 的义务与责任, 并利用法律手段促进源头污染的治 理。其次, 应加快修订采矿业能源消耗、污染物排 放、环境质量等标准,提高行业的环境准人门槛。 再次,针对不同资源开采产生的地质和环境问题的 差异性, 有针对性地进行环境规制, 防止“一刀切” 带来的资源投人错位与浪费。政府还应加强资源 开发活动的生态环境监管力度, 强化环境执法, 对 资源开采造成的环境违法、违规行为 “零容忍”。特 别地, 煤炭和有色金属开采业是环境污染和生态破 坏的主要来源, 需进行重点监管, 例如, 继续削减矿 山企业废水、废气和固体废弃物的排放总量额度; 以及利用行政、法律、经济与技术等多种手段,提高 矿产资源尾矿利用率和选矿回收率等。

第二, 采矿业规模报酬递增趋势显著, 且对绿 色全要素生产率的提升具有正向作用,因此,政府
应进一步整合行业资源,提高产业集中度。近年 来, 中国在煤炭、稀土等行业进行的以国企为龙头 的整合,极大地提高了资源开采的集约化程度,企 业利润、生产率等指标都得到一定程度的改善。然 而,2017年煤炭、黑色金属、有色金属等行业的大中 型企业数量仍有 $1428 、 246 、 333$ 家, 存在进一步整合 和压缩的空间。此外,应继续优化采矿企业的成本 结构,发挥规模经济效应。但需注意的是,在减少 无效供给、淘汰落后产能的同时,也需预防在经济 下行时期新增落后产能或关停企业“死灰复燃”等 问题。

第三,纯技术进步是绿色全要素生产率增长的 主要来源之一, 因而, 政府应继续鼓励采矿业进行 绿色技术升级。但在不同的子行业,政策重点应有 所侧重。在竞争性较强的行业,政府应采用研发补 贴、税收优惠等方式鼓励采矿企业持续增加绿色技术 研发投人,提升技术创新能力,改善创新绩效;在竞 争不足的油气开采业,应积极推进国有企业的混合所 有制改革,提高企业投资激励和经营效率; 更重要 的是破除所有制、市场准人与退出等方面对民营企 业的歧视,激发行业竞争活力,强化企业创新动力。

\section{参考文献(References):}

[1] 中华人民共和国国家统计局. 中国统计年鉴[M]. 北京: 中国统 计出版社, 2017. [National Bureau of Statistic of China. China Statistic Yearbook[M]. Beijing: China Statistic Press, 2017.]

[2] Li J C, Yu L H. How does state-owned shares affect double externalities and industrial performance: Evidence from China's exhaustible resources industry[J]. Journal of Cleaner Production, 2018, 176: 920-928.

[3] 中共中央国务院. 中共中央国务院关于加快推进生态文明建 设的意见 [EB/OL]. (2015-05-05) [2019-05-21]. http: //www. gov. cn/xinwen/2015-05/05/content_2857363. htm. [The State Council of the CPC Central Committee. Opinions of the Central Committee of the CPC and the State Council on Accelerating the Promotion of Ecological Progress[EB/OL]. (2015- 05- 05) [201905-21]. http: //www.gov.cn/xinwen/2015-05/05/content_2857363. htm.]

[4] 李维明, 高世楫. 经合组织关于绿色全要素生产率核算方法的 探索及启示[J]. 发展研究, 2018, (7): 52-57. [Li W M, Gao S J. OECD's research and inspiration on GTFP calculating method[J]. Development Research, 2018, (7): 52-57.] 
[5]陈阳, 唐晓华. 制造业集聚对城市绿色全要素生产率的溢出效 应研究: 基于城市等级视角[J]. 财贸研究, 2018, 29(1): 1-15. [Chen Y, Tang X H. Spillover effects of manufacturing agglomeration on urban green total factor productivity: Based on the perspective of urban grade[J]. Finance and Trade Research, 2018, 29(1): $1-15$.

[6] 陈阳, 唐晓华. 制造业集聚和城市规模对城市绿色全要素生产 率的协同效应研究[J]. 南方经济, 2019, 38(3): 71-89. [Chen Y, Tang X H. Study on the synergistic effect of manufacturing agglomeration and urban size on urban green total factor productivity[J]. South China Journal of Economics, 2019, 38(3): 71-89.]

[7] 齐绍洲, 徐佳. 贸易开放对“一带一路”沿线国家绿色全要素生 产率的影响[J]. 中国人口・资源与环境, 2018, 28(4): 134-144. [Qi S Z, Xu J. Influence of trade openness on green TFP of countries along 'the Belt and Road' [J]. China Population, Resources and Environment, 2018, 28(4): 134-144.]

[8] Hoteling H. The economics of exhaustible resources[J]. Journal of Political Economy, 1931, 39(2): 137-175.

[9] Arrow K, Chang S. Optimal pricing, use and exploration of uncertain natural resource stocks[J]. Journal of Environmental Economics and Management, 1982, 9(1): 1-10.

[10] Solow R M. The economics of resources and the resources of economics[J]. American Economic Review, 1974, 64(2): 1-14.

[11] Ayres R U, Kneese A V. Production, consumption and externalities [J]. American Economic Review, 1969, 59(3): 282-297.

[12] 李平. 中国工业绿色转型研究[J]. 中国工业经济, 2011, (4): 514. [Li P. A study on the green transformation of Chinese industry [J]. China Industrial Economics, 2011, (4): 5-14.]

[13] 吴军. 环境约束下中国地区工业全要素生产率增长及收玫分析 [J]. 数量经济技术经济研究, 2009, 26(11): 17-27. [Wu J. TFP growth and convergence across China's industrial economy considering environmental protection[J]. The Journal of Quantitative \&Technical Economics, 2009, 26(11): 17-27.]

[14] 王永卿, 王来峰, 邓洪星, 等. 湖北省绿色矿山建设影响因素及 其效果分析[J]. 资源科学, 2019, 41(8): 1513-1525. [Wang Y Q, Wang L F, Deng H X, et al. Influencing factors and performance evaluation of green mining in Hubei Province[J]. Resources Science, 2019, 41(8): 1513-1525.]

[15] Ramanathan R. An analysis of energy consumption and carbon dioxide emissions in countries of the middle east and north Africa [J]. Energy, 2005, 30(15): 2831-2842.

[16] 展进涛, 徐钰娇, 葛继红. 考虑碳排放成本的中国农业绿色全要 素变化[J]. 资源科学, 2019, 41(5): 884-896. [Zhan J T, Xu Y J, Ge J H. Change in agricultural green productivity in China considering the cost of carbon emissions[J]. Resources Science, 2019, 41 (5): 884-896.]

[17] 陈晓, 车治辂. 中国区域经济增长的绿色化进程研究[J]. 上海经 济研究, 2018, (7): 43-53. [Chen X, Che Z L. Study on the green process of regional economic growth in China[J]. Shanghai Journal of Economics, 2018, (7): 43-53.]

[18] 岳鸿飞, 徐颖, 周静. 中国工业绿色全要素生产率及技术创新贡 献测评[J]. 上海经济研究, 2018, (4): 52-61. [Yue H F, Xu Y, Zhou J. Assessment of China's industrial green total factor productivity and technological innovation contribution[J]. Shanghai Journal of Economics, 2018, (4): 52-61.]

[19] 潘丹,应瑞瑶. 资源环境约束下的中国农业全要素生产率增长 研究[J]. 资源科学, 2013, 35(7): 1329-1338. [Pan D, Ying R Y. Agricultural total factor productivity growth in China under the binding of resource and environment[J]. Resources Science, 2013 35(7): 1329-1338.]

[20] 陈诗一. 中国工业分行业统计数据估算: 1980-2008[J]. 经济学 (季刊), 2011, 10(3): 735-776. [Chen S Y. Reconstruction of subindustrial statistical data in China: 1980-2008[J]. China Economic Quarterly, 2011, 10(3): 735-776.]

[21] 向小东, 林健. 中国工业企业创新全要素生产率评价: 基于双前 沿面网络 DEA-Malmquist 指数模型[J]. 工业技术经济, 2017, 36 (9): 93-103. [Xiang X D, Lin J. Evaluation of total factor productivity of innovation in China's industrial enterprises: Based on the double frontiers network DEA-Malmquist index model[J]. Journal of Industrial Technological \& Economics, 2017, 36(9): 93-103.]

[22] 杨茜淋. 我国工业分行业全要素生产率估计[J]. 商业时代, 2013, (16): 115-117. [Yang Q L. Estimation of total factor productivity in China's industrial sectors[J]. Commercial Times, 2013, (16): 115-117.]

[23] 张豪, 张一弛, 张建华. 中国行业间全要素生产率的溢出效应与 增长源泉: 基于 10 大行业的经验研究[J]. 华东经济管理, 2017, 31(4): 89-96. [Zhang H, Zhang Y C, Zhang J H. Total factor productivity spillover effects between industries and growth sources in China: Based on the 10 major industries' experience research [J]. East China Economic Management, 2017, 31(4): 89-96.]

[24] 陈超凡. 中国工业绿色全要素生产率及其影响因素: 基于 ML 生产率指数及动态面板模型的实证研究 [J]. 统计研究, 2016 , 33(3): 53-62. [Chen C F. China's industrial green total factor productivity and its determinants: An empirical study based on ML index and dynamic panel data model[J]. Statistic Research, 2016, 33 (3): 53-62.]

[25] 赵萌. 中国煤炭企业的全要素生产率增长[J]. 统计研究, 2011 , 28(8): 55-62. [Zhao M. Total factor productivity growth of Chinese coal industry[J]. Statistic Research, 2011, 28(8): 55-62.]

[26] Rodriguez A, Arias C. The effects of resource depletion on coa mining productivity[J]. Energy Economics, 2008, 30(2): 397-408.

[27] 王克强, 武英涛, 刘红梅. 中国能源开采业全要素生产率的测度 框架与实证研究[J]. 经济研究, 2013, 48(6): 127-140. [Wang K Q, Wu Y T, Liu H M. An analytical framework and empirical study for TFP in Chinese energy mining industry[J]. Economic Research Journal, 2013, 48(6): 127-140. 
[28] Malmquist S. Index numbers and indifference surfaces[J]. Trabajos De Estadistica, 1953, 4(2): 209-242.

[29] Aigner D, Knox L, Peter S. Formulation and estimation of stochastic frontier production function models[J]. Journal of Econometrics, $1977,6(1): 21-37$.

[30] Afriat N. Efficiency estimation of production functions[J]. International Economic Review, 1972, 13(3): 568-598.

[31] 张峰, 宋晓娜. 提高环境规制能促进高端制造业“绿色蜕变”吗: 来自绿色全要素生产率的证据解释[J]. 科技进步与对策, 2019, 36(21): 53-61. [Zhang F, Song X N. Can environmental regulation improve the "green transformation" of high-end manufacturing? Evidence interpretation from green total factor productivity [J]. Science \& Technology Progress and Policy, 2019, 36(21): 53-61.]

[32] 肖漟, 卢丽文. 资源型城市工业绿色转型发展测度: 基于全国 108 个资源型城市的面板数据分析[J]. 财经科学, 2019, (9): 8698. [Xiao Y, Lu L W. Measurement of industrial green transformation efficiency in resource-based cities: Based on 108 resourcebased cities' panel data[J]. Finance \& Economics, 2019, (9): 8698.]

[33] 陈瑶. 中国区域工业绿色发展效率评估[J]. 经济问题, 2018, (12): 77-83. [Chen Y. Efficiency evaluation of China's regional industrial green development: Based on the perspective of R\&D input[J]. On Economic Problems, 2018, (12): 77-83.]

[34] 黄庆华, 胡江峰, 陈习定. 环境规制与绿色全要素生产率: 两难 还是双赢?[J]. 中国人口·资源与环境, 2018, 28(11): 140-149. [Huang Q H, Hu J F, Chen X D. Environmental regulation and green total factor productivity: Dilemma or win-win? [J]. China Population, Resources and Environment, 2018, 28(11): 140-149.]

[35] 孙才志, 马奇飞, 赵良仕. 基于 SBM-Malmquist生产率指数模型 的中国水资源绿色效率变动研究 [J]. 资源科学, 2018, 40(5): 993-1005. [Sun C Z, Ma Q F, Zhao L S. Green efficiency changes for water resources in China based on SBM-Malmquist model[J]. Resources Science, 2018, 40(5): 993-1005.]

[36] 杨勇, 李忠民. 供给侧结构性改革背景下的要素市场化与工业 全要素生产率: 基于 31 个地区的实证分析[J]. 经济问题探索, 2017, (2): 31-38. [Yang Y, Li Z M. Factor marketization and industrial total factor productivity under the background of supplyside structural reform: An empirical analysis based on 31 regions [J]. Inquiry into Economic Issues, 2017, (2): 31-38.]

[37] Solminihac D, Gonzales L E, Cerda R. Copper mining productivity: Lessons from Chile[J]. Journal of Policy Modeling, 2017, 40(1): $182-193$.

[38] 陈林, 朱沛华. 一种新的考虑全要素生产率的成本函数估计法 [J]. 数量经济技术经济研究, 2017, 34(5): 88-106. [Chen L, Zhu P H. A new method of estimating the cost function by considering total factor productivity[J]. The Journal of Quantitative \& Technical Economics, 2017, 34(5): 88-106.]
[39] Topp V. Productivity in the mining industry: Measurement and interpretation[J]. Productivity Commission Staff Working Papers, 2008, 12(2): 176-200.

[40] Simom Z, Harry B. Australia's mining productivity decline: Implications for MFP measurement[J]. Journal of Productivity Analysis, 2014, 41(2): 201-212.

[41] 林伯强, 何晓萍. 中国油气资源耗减成本及政策选择的宏观经 济影响[J]. 经济研究, 2008, (5): 94-104. [Lin B Q, He X P. Chinese oil and gas depletion costs and macroeconomic impacts of resource tax[J]. Economic Research Journal, 2008, (5): 94-104.]

[42] 李国平, 杨洋. 中国煤炭和石油天然气开发中的使用者成本测 算与价值补偿研究 [J]. 中国地质大学学报(社会科学版), 2009, 9(5): 36-42. [Li G P, Yang Y. User cost of the exploitation of coal and oil \& natural gas resource and value compensation in China [J]. Journal of China University of Geosciences (Social Sciences Edition), 2009, 9(5): 36-42.

[43] 宋益, 黄健柏, 钟美瑞, 等. 外部性成本内部化视角下战略性矿 产资源关税替代性政策研究: 以稀土矿为例 [J]. 资源科学, 2018, 40(3): 611-622. [Song Y, Huang J B, Zhong M R, et al. Research on tariffs' alternative policy of strategic mineral resources from the perspective of externality cost internalization taking rare earth mine as an example[J]. Resources Science, 2018, 40(3): 611622.]

[44] 郭江, 铁卫, 李国平. 运用 CVM 评估煤炭矿区生态环境外部成 本的测算尺度选择研究: 基于有效性和可靠性分析视角 [J]. 生 态经济, 2018, 34(8): 163-168. [Guo J, Tie W, Li G P. A study on the selection of measurement scale using CVM to evaluate the external cost of ecological environment in coal mining area: Based on validity and reliability analysis[J]. Ecological Economy, 2018, 34(8): 163-168.]

[45] 吴文洁, 常志风. 油气资源开发生态补偿标准模型研究[J]. 中国 人口・资源与环境, 2011, 21(5): 26-30. [Wu W J, Chang Z F. Research on eco-compensation standard model for oil-gas exploitation[J]. China Population, Resources and Environment, 2011, 21 (5): 26-30.]

[46] 周吉光, 丁欣. 河北省矿产资源开采造成的环境损耗的经济计 量 [J]. 资源与产业, 2012, 14(6): 148-155. [Zhou J G, Ding X. Economic measurement of environmental loss brought by mineral resources exploitation in Hebei Province[J]. Resource \& Industries, 2012, 14(6): 148-155.]

[47] 贾舒娴, 黄健柏, 钟美瑞. 生态文明建设背景下江西省有色金属 矿产开发生态影响能值分析[J]. 长江流域资源与环境, 2017, 26(9): 1378-1387. [Jia S X, Huang J B, Zhong M R. Energy analysis of the development of nonferrous metals in Jiangxi Province under the background of ecological civilization construction[J]. Resources and Environment in the Yangtze Basin, 2017, 26(9): 1378-1387. 


\title{
Green total factor productivity of Chinese mining industries considering negative intergenerational and environmental externalities
}

\author{
YU Lihong, WANG Yan, CHEN Jiayi \\ (School of Business, East China University of Science and Technology, Shanghai 200237, China)
}

\begin{abstract}
Negative intergenerational and environmental externalities are the basic characteristics of Chinese mining industries. Total factor productivity (TFP) had not taken dual negative externalities into account, while most studies on green total factor productivity (GTFP) only considered environmental pollution, and therefore it is difficult to measure the true efficiency of green technology in mining industries. In this study, dual negative externalities were added into the modified Solow residual model to measure the growth rate of GTFP based on the inter-provincial panel data of mining industries from 2005 to 2015, and then GTFPs were decomposed into the effects of technological progress, returns to scale, negative intergenerational externality, negative environmental externality, and so on. The results show that: (1) GTFP was generally lower than TFP without dual negative externalities, and the overall trend was more stable. (2) The GTFP of mining industries presented a clear increasing tendency. Ferrous metal mining industry had the fastest growth rate, followed by coal mining industry and nonferrous metal mining industry, and oil and gas mining industry had the lowest growth rate. (3) The decomposition of GTFP shows that negative intergenerational and environmental externalities both restrained GTFP. Through a comparative analysis, we found that coal and nonferrous metal industries were greatly affected by negative environmental externality, while extraction of oil and gas and ferrous metal mining were more affected by negative intergenerational externality.
\end{abstract}

Key words: mining industry; green total factor productivity; negative intergenerational externality; negative environmental externality 